\title{
Wide-Tunable Low-Field Interdigitated Barium Strontium Titanate Capacitors
}

\author{
Mahmoud Al Ahmad, Member, IEEE, Magali Brunet, Sandrine Payan, Dominique Michau, Mario Maglione, and \\ Robert Plana, Member, IEEE
}

\begin{abstract}
This letter reports low-field wide-tunable interdigitated barium strontium titanate (BST) capacitors. The capacitors consisting of BST thin film dielectric, silicon substrate, and gold metallization have been fabricated. The capacitance exhibits $0.2 \mathrm{pF}$ at zero-bias and shows a tunability of $63 \%$ with an applied electric field of $1.4 \mathrm{~V} / \mu \mathrm{m}$. This corresponds to a $3.5 \mu \mathrm{m}$ electrode gap width and a $5 \mathrm{~V}$ dc bias. Microwave measurements reveal a zero bias film quality of 50 around $30 \mathrm{GHz}$.
\end{abstract}

Index Terms-Barium strontium titanate (BST), capacitors, thin film, tunable circuit, varactors.

\section{INTRODUCTION}

$\mathbf{I}$ NTEGRATED barium strontium titanate (BST) voltagecontrolled capacitors are core components in tunable radio frequency (RF) and microwave devices such as voltage controlled oscillators (VCOs) [1]-[3], tunable filters [4], [5], phase shifters [6], [7], and tunable matching networks [8], [9]. A varactor with high quality factor and large tuning range is a mandatory prerequisite to meet the requirements of high tunable components specifications [10]. The quality of the BST thin film depends on its processing conditions such as temperature, thickness and substrate [11]. The interdigital capacitor (IDC) fingers provide coupling between the input and output ports across the gaps. The major challenge in the fabrication of such structures is maintaining narrow gaps for high tunability, while simultaneously forming thick electrodes to minimize RF loss [12]. The metallization and patterning by photolithography are key issues in the fabrication of such structures which are formed by the deposition of metal on a single side of a BST film [13]. However, due to the difficulty of forming high aspect ratio photoresist molds with the required pattern resolution, it is difficult to fabricate tall and narrow gap electrodes .

In this work, $3.5 \mu \mathrm{m}$ gap BST interdigital capacitor exhibiting high tunability at low bias field is presented. The tunability of $3: 1$ is obtained at bias voltage of $5 \mathrm{~V}$. Furthermore, loss tangent of the BST thin film is found to be approximately 0.0204 at $30 \mathrm{GHz}$.

M. A. Ahmad, M. Brunet, and R. Plana are with LAAS CNRS, Université de Toulouse, Toulouse F-31077, France (e-mail: al-ahmad.mahmoud@ @ieee.org; m_al_ahmad@hotmail.com).

S. Payan, D. Michau, and M. Maglione are with ICMCB CNRS, Université de Bordeaux, Pessac F-33608, France (e-mail: maglione@icmcb-bordeaux.cnrs. fr).

\section{INTERDIGITATED CAPACITOR DESIGN AND FABRICATION}

Interdigitated capacitor structures were achieved by lift-off process [14]. The structure has 16 fingers of width $3.5 \mu \mathrm{m}$, length of $100 \mu \mathrm{m}$ and spacing of $3.5 \mu \mathrm{m}$. The $\mathrm{Ba}_{0.6} \mathrm{Sr}_{0.4} \mathrm{TiO}_{3}$ thin films were deposited by radio frequency sputtering using home made targets of 2 in diameter. The power density was $3 \mathrm{~W} / \mathrm{cm}^{2}$, the distance between the target and the substrate was $55 \mathrm{~mm}$ and the $15 \times 15 \mathrm{~mm}^{2}$ substrate temperature was $650{ }^{\circ} \mathrm{C}$. The total pressure and oxygen partial pressure were tuned as to reach the right film stoechiometry as checked by Rutherford Backscattering. The optimal parameters to achieve this good BST stoechiometry were a base pressure of $6 \times 10^{-5} \mathrm{~Pa}$, a total Argon + Oxygen pressure of $5 \mathrm{~Pa}$ and an Oxygen partial pressure of $1 \%$. Prior to the film deposition a pre-sputtering of $1 \mathrm{~h}$ was undertaken as to fix the target surface. Prior to the electrodes deposition, the sample's surface was cleaned by a soft $\mathrm{O}_{2}$ plasma treatment and baked in oven $\left(200^{\circ} \mathrm{C}, 30 \mathrm{~min}\right)$. Then, top electrodes pattern was designed by lithography insolation of a photoresist resin through a shadow mask. $400 \mathrm{~nm}$-thick Au electrodes were deposited by evaporation. To ensure the adherence of the noble metal film, a Ti layer $(50 \mathrm{~nm})$ was deposited prior to Au deposition. After the resin removing and an anneal step in a furnace $\left(250^{\circ} \mathrm{C} / 20 \mathrm{~min}\right)$. The final device is shown in Fig. 1(a).

\section{MEASUREMENTS AND ANALYSIS}

The device has been measured using a network analyzer. The device consists of two independent tunable capacitors with common ground. The two interdigited capacitors have been activated by applying a dc bias on the signal lines. The measured transmission coefficients as a function of frequency for different bias voltages are shown in Fig. 2(a). It is evident that the two capacitors are isolated from each other by more than $45 \mathrm{~dB}$ which is good enough to decouple them. Hence, any information about the device performance, material characterizations and modeling are constructed from its reflection coefficients.

Fig. 2(b) shows the measured reflection coefficients of the device. The tunability is more pronounced at higher frequencies due to the value of the tuned capacitance which exhibits a low value. The corresponding equivalent circuit has been constructed based on the physical geometry of the structure and is shown in Fig. 1(b). The values of the circuit elements were first calculated by using the general relation between the distributed and the lumped elements [15]. Then these computed values were adjusted by matching the equivalent circuit performance with the measured. The set of elements, $L, C$ and $R_{p}$, represent the shunt-stub corresponding inductance, inherent capacitance and 


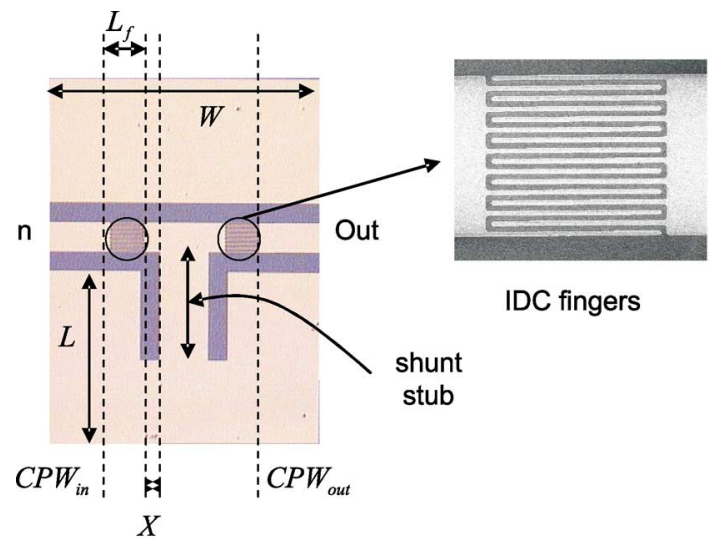

(a)

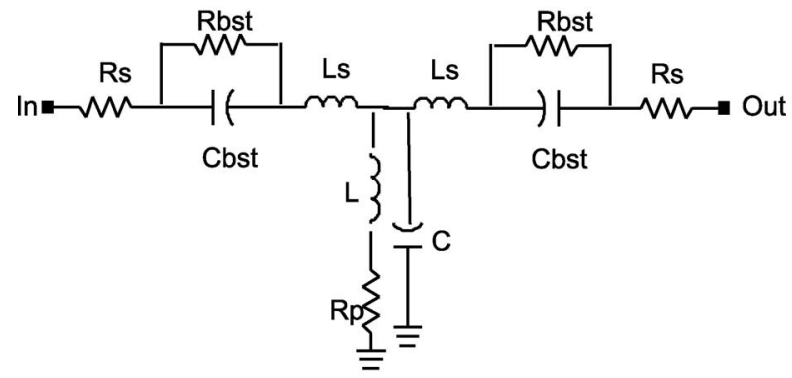

(b)

Fig. 1. Fabricated device and its equivalent circuit: (a) test structure with $W$, $L_{f}, L$ and $X$ are of $850,100,350$, and $50 \mu \mathrm{m}$ respectively. CPWs are with GSG of $60-100-60 \mu \mathrm{m}$. Shunt stub of length $340 \mu \mathrm{m}$ and width of $150 \mu \mathrm{m}$; (b) lumped element representations: $R s, L s, R p, L, C$ are $0.5 \Omega, 0.0712 \mathrm{nH}, 3.7 \Omega$, $0.0125 \mathrm{pF}$, respectively. Rbst and $C b s t$ are of $1300 \Omega$ and $0.2 \mathrm{pF}$, respectively, at zero bias.

losses, respectively. Due to the wide slot of the CPW line, i.e., $60 \mu \mathrm{m}$, the BST material is not activated within the slots, thus these set of elements are not tuned. The variation in the dielectric constant of the BST thin-film due to the applied electric field results in a tunable capacitance which is generally modeled by a lumped capacitance of value $C_{\mathrm{bst}}$. The thin-film quality modeled in terms of parallel resistance of $R_{\mathrm{bst}}$, while the conductor losses are represented by $R_{s}$. $L_{s}$ represents the inductance of the CPW access and capacitor fingers. Fig. 2(b) also shows the good fitting between the measurements and the equivalent circuit performance for zero bias. The tuned capacitance $C_{\mathrm{bst}}$ exhibits a tunability of $63 \%$ with the application of applied field of $1.4 \mathrm{~V} / \mu \mathrm{m}$. Up to our knowledge this is the lowest tuning field ever reported.

The film quality factor is computed from the inverse of the dielectric loss factor $\tan (\delta)$. This dielectric loss is calculated using (1) and the equivalent circuit parameters, namely the shunt resistance $R_{\mathrm{bst}}$ which models the losses of the dielectric and the $C_{\mathrm{bst}}$ which represent the capacitance tuned value, the loss tangent, $\tan (\delta)$, is then calculated [16] as follows:

$$
\tan (\delta)=\left(\omega R_{\mathrm{bst}} C_{\mathrm{bst}}\right)^{-1}
$$

where $\omega$ is the angular frequency. At $30 \mathrm{GHz}$, the $\tan (\delta)$ is found to be 0.0204 , i.e., film quality of 50. Fig. 3 shows the permittivity and losses voltage-dependence in the dielectric material.

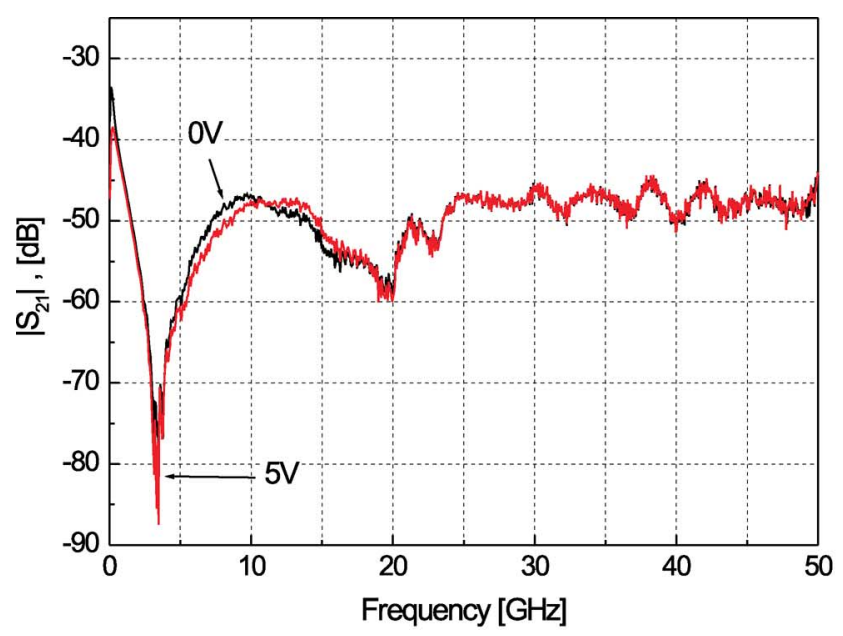

(a)

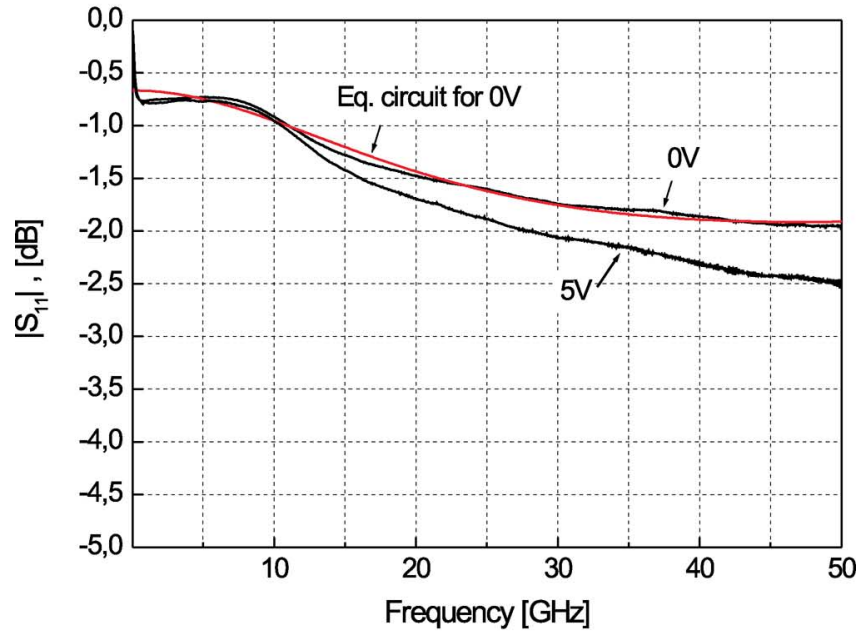

(b)

Fig. 2. Microwave measurements of the device shown on Fig. 1(a): (a) the $\left|S_{21}\right|$ transmission coefficient and (b) the $\left|S_{11}\right|$ reflection coefficient and the circuit model.

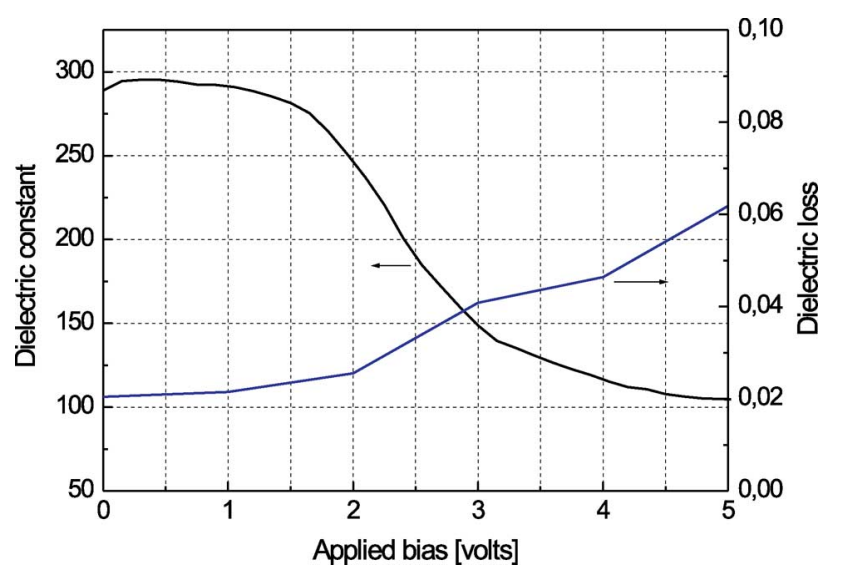

Fig. 3. Tunability of the material permittivity at the $\mathrm{GHz}$ range of the device shown on Fig. 1(a).

The BST material exhibits unavoidable intrinsic losses at high frequency, thus limiting their based devices performances. The limitation of device quality factor due to its ohmic losses can be avoided by thicker metallizations. 


\begin{tabular}{lllll}
\hline & $\begin{array}{l}\text { Tunability } \\
{[\%]}\end{array}$ & $\begin{array}{l}\text { Electric field } \\
{[\mathrm{V} / \mu \mathrm{m}]}\end{array}$ & $\begin{array}{l}\text { Capacitance } \\
{[\mathrm{pF}]}\end{array}$ & $\begin{array}{l}\text { Quality } \\
{[@ \mathrm{n} \mathrm{GHz}]}\end{array}$ \\
\hline This work & 63 & 1.4 & 0.2 & $50(30)$ \\
{$[17]$} & 40 & 11.6 & 0.6 & $30(26)$ \\
{$[18]$} & 26 & 40 & 7 & $20(24)$ \\
{$[19]$} & 64 & 35 & 3.5 & $27(2.4)$ \\
{$[20]$} & 40 & 13.3 & 0.4 & $9(9)$ \\
{$[21]$} & 65 & 7 & 1.9 & $4(20)$ \\
\hline
\end{tabular}

[6] E. G. Erker, A. S. Niagra, Y. Liu, P. Periaswamy, T. R. Taylor, J. Speck, and R. A. York, "Monolithic Ka band phase shifter using voltage variable $\mathrm{BaSrTiO} 3$ parallel plate capacitor," IEEE Microw. Guided Wave Lett., vol. 10, no. 1, pp. 10-12, Jan. 2000.

[7] D. Kim, Y. Choi, M. G. Allen, J. S. Kenney, and D. Kiesling, "A wide-band reflection-type phase shifter at S-band using BST coated substrate," IEEE Trans. Microw. Theory Tech., vol. 50, no. 12, pp. 2903-2909, Dec. 2002

[8] L.-Y. V. Chen, R. Forse, D. Chase, and R. A. York, "Analog tunable matching network using integrated thin-film BST capacitors," in IEEE MTT-S Int. Dig., 2004, vol. 1, pp. 261-264.

[9] P. Scheele, F. Goelden, A. Giere, S. Mueller, and R. Jakoby, "Continuously tunable impedance matching network using ferroelectric varactors," in IEEE MTT-S Int. Dig., 2005, pp. 603-606.

[10] M. Rahman and K. Shamsaifar, "Electronically tunable LTCC based multi-layer filter for mobile handset application," in IEEE MTT-S Int. Dig., 2003, vol. 3, pp. 1767-1770.

Finally, we compare the present data with several recent literature examples as shown in Table I [17]-[21]. These data illustrate that this work reports the lowest required tuning field preserving a wide tunability.

\section{CONCLUSION}

Interdigitated BST capacitors with both wide tunability and low biasing field have been processed. The capacitance exhibits its maximum value of $0.2 \mathrm{pF}$ at zero bias. A tunability ratio of $3: 1$ with the application of low field $1.4 \mathrm{~V} / \mu \mathrm{m}$ is observed. This is the lowest applied field with such high tunability that ever reported comparable to results reported in the literature by other groups.

\section{REFERENCES}

[1] A. Jamil, T. S. Kalkur, and N. Cramer, "Tunable ferroelectric capacitor-based voltage-controlled oscillator," IEEE Trans. Ultrason., Ferroelectr. Freq. Contr., vol. 54, no. 2, pp. 222-226, Feb. 2007.

[2] A. Victor, J. Nath, D. Ghosh, B. Boyette, J.-P. Maria, M. B. Steer, A. I. Kingon, and G. T. Stauf, "A voltage controlled oscillator using barium strontium titanate (BST) thin film varactor," in Proc. IEEE Rad. Wireless Conf., 2004, pp. 91-94.

[3] M. Al-Ahmad, C. Loyez, N. Rolland, and P.-A. Rolland, "Wide BSTbased tuning of voltage controlled oscillator," in Proc. Asia-Pacific Microw. Conf. (APMC'06), 2006, [CD ROM].

[4] A. Tombak, J.-P. Maria, F. T. Ayguavives, J. Zhang, G. T. Stauf, A. I. Kingon, and A. Mortazawi, "Voltage-controlled RF filters employing thin-film barium-strontium-titanate tunable capacitors," IEEE Trans. Microw. Theory Tech., vol. 51, no. 2, pt. 1, pp. 462-467, Feb. 2003.

[5] J. Papapolymerou, C. Lugo, Z. Zhiyong, W. Xiaoyan, and A. Hunt, "A miniature low-loss slow-wave tunable ferroelectric bandpass filter from 11-14 GHz," in IEEE MTT-S Int. Dig., 2006, pp. 556-559.

[11] R. Jakoby, P. Scheele, S. Muller, and C. Weil, "Nonlinear dielectrics for tunable microwave components," in Proc. 15th Int. Conf. Microw., Radar Wireless Commun., 2004, vol. 2, pp. 369-378.

[12] Y.-K. Yoon, M. G. Allen, and A. T. Hunt, "Tunable ferroelectric capacitor with low-loss electrodes fabricated using reverse side exposure," in Proc. 53rd Electron. Compon. Technol. Conf., 2003, pp. 1534-1540.

[13] J. Nath, D. Ghosh, J. P. Maria, M. B. Steer, A. I. Kingon, and G. T. Stauf, "Microwave properties of bst thin film interdigital capacitors on low cost alumina substrates," in Proc. 34th Eur. Microw. Conf., Oct. 2004, pp. 1497-1500.

[14] M. Ouaddari, S. Delprat, F. Vidal, M. Chaker, and K. Wu, "Microwave characterization of ferroelectric thin-film materials," IEEE Trans. Microw. Theory Tech., vol. 53, no. 4, pt. 1, pp. 1390-1397, Apr. 2005.

[15] R. Mongia, I. Bahl, and B. Prakash, RF and Microwave Coupled Line Circuits. London, U.K.: Artech House, 1999.

[16] Z. Jin, A. Tombak, J.-P. Maria, B. Boyette, G. T. Stauf, A. I. Kingon, and A. Mortazawi, "Microwave characterization of thin film BST material using a simple measurement technique," in IEEE MTT-S Int. Dig., 2002, vol. 2, pp. 1201-1204.

[17] D. Ghosh, B. Laughlin, J. Nath, A. I. Kingon, M. B. Steer, and J.-P. Maria, "Tunable high-quality-factor interdigitated (Ba,Sr)TiO3 capacitors fabricated on low-cost substrates with copper metallization," Thin Slolid Films, vol. 496, no. 2, pp. 669-673, Feb. 2006.

[18] Y. Liu, A. S. Nagra, E. G. Erker, P. Periaswamy, T. R. Taylor, J. Speck, and R. A. York, "BaSrTiO3 interdigitated capacitors for distributed phase shifter applications," IEEE Microw. Guided Wave Lett., vol. 10, pp. 448-450, 2000.

[19] D. Kim, Y. Choi, M. Ahn, M. G. Allen, J. S. Kenney, and P. Marry, "2.4 $\mathrm{GHz}$ continuously variable ferroelectric phase shifters using all-pass networks," IEEE Microw. Wireless Compon. Lett., vol. 13, no. 10, pp. 434-436, Oct. 2003.

[20] S. E. Moon, E.-Y. Kim, M.-H. Kwak, H.-C. Ryu, Y.-T. Kim, K.-Y Kang, S.-J. Lee, and W.-J. Kim, "Orientation dependent microwave dielectric properties of ferroelectric $\mathrm{Ba}_{1-\mathrm{x}} \mathrm{Sr}_{\mathrm{x}} \mathrm{TiO} 3$ thin films," Appl. Phys. Lett., vol. 83, pp. 2166-2168, Sep. 2003.

[21] J. Bellotti, E. K. Akdogan, A. Safari, W. Chang, and S. Kirchoefer, "Tunable dielectric properties of BST thin films for RF/MW passive components," Integr. Ferroelect., vol. 49, no. 1, pp. 113-122, 2002. 